\title{
Correction to: Effectiveness of glutamine in the management of oral mucositis in cancer patients: a meta-analysis of randomized controlled trials
}

\author{
Tzu-Rong Peng ${ }^{1} \cdot$ Hung-Hong Lin ${ }^{2} \cdot$ Li-Jou Yang ${ }^{1} \cdot$ Ta-Wei Wu ${ }^{1,3}$ \\ Published online: 13 May 2021 \\ (C) Springer-Verlag GmbH Germany, part of Springer Nature 2021
}

Correction to: Supportive Care in Cancer https://doi.org/10.1007/s00520-021-06060-9

The Electronic Supplementary Material is incorrect in the original article and is corrected in this article.

The original article has been corrected.

Supplementary Information The online version contains supplementary material available at https://doi.org/10.1007/s00520-021-06112-0.

Publisher's note Springer Nature remains neutral with regard to jurisdictional claims in published maps and institutional affiliations.

The online version of the original article can be found at https://doi.org/ 10.1007/s00520-021-06060-9

Ta-Wei Wu

p8561825@yahoo.com.tw

1 Department of Pharmacy, Taipei Tzu ChiHospital, Buddhist Tzu Chi Medical Foundation, \#289, Jianguo Road, Xindian District, New Taipei City 23142, Taiwan

2 Department of Pharmacy, Chia-Nan University of Pharmacy and Science, Tainan, Taiwan

3 School of Pharmacy, College of Pharmacy, Taipei Medical University, Taipei, Taiwan 